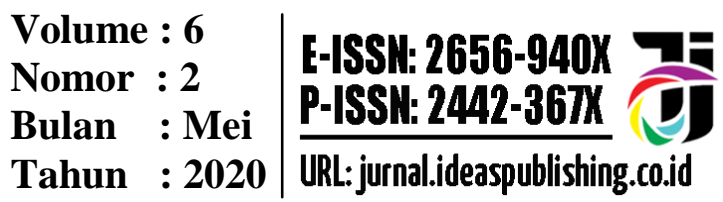

\title{
Makna Perkawinan Sedarah bagi Warga Suku Polahi di Indonesia
}

\author{
Apris Ara Tilome \\ Universitas Muhammadiyah Gorontalo \\ Pos-el: aprisaratilome@gmail.com \\ Ramlah Alkatiri \\ Universitas Muhammadiyah Gorontalo \\ Pos-el: alkatiri.ramlah@gmail.com
}

DOI: $10.32884 /$ ideas.v\% vi\%i.237

\begin{abstract}
Abstrak
Perkawinan biasanya dilakukan oleh dua lawan jenis dari keluarga yang berbeda dan tanpa ikatan darah di antara mereka. Berbeda dengan suku Polahi di Gorontalo yang memiliki budaya sistem kawin sedarah atau sistem perkawinan inses yang secara genetis berbahaya bagi keturunan yang dilahirkan. Penelitian ini menggunakan studi dokumen dan wawancara. Data hasil penelitian dianalisis menggunakan metode kualitatif. Penelitian ini dikaitkan dengan berbagai aspek dan sudut pandang yaitu aspek agama, hukum dan undang-undang, kesehatan, sosial dan budaya. Hasil penelitian menunjukkan bahwa perkawinan sedarah bagi suku polahi bukan karena adat kebiasaan, akan tetapi pemahaman dan pengetahuan yang sangat kurang, bahkan nyaris tidak mengetahui apa-apa tentang pergaulan sesama kelompok. Fakta di lapangan memperlihatkan tidak adanya pengaruh keturunan dari hasil pernikahan inses suku Polahi ini, namun tetap untuk menghindari larangan agama mau larangan secara medis harus ada upaya untuk memberi pemahaman pengetahuan kepada warga suku Polahi.
\end{abstract}

Kata kunci: pernikahan sedarah, inses, budaya, suku Polahi

\section{Pendahuluan}

Manusia sebagai makhluk sosial tidak mungkin dapat hidup sendiri. Ia pasti membutuhkan orang lain untuk berkomunikasi, melaksanakan tugas, dan memenuhi segala kebutuhanya. Selain itu manusia juga dikaruniai nafsu berupa kecenderungan tabiat kepada sesuatu yang dirasa cocok. Kecenderungan ini merupakan satu bentuk ciptaan yang ada pada diri manusia, sebagai urgensi kelangsungan hidupnya. Seperti makan, minum, dan menikah. Pernikahan adalah suatu hal suci yang menggabungkan dua orang berbeda menjadi satu dan membentuk satu keluarga yang baru.

Pernikahan merupakan salah satu bagian dari kehidupan yang dilalui manusia untuk melanjutkan keturunan. Dalam perspektif sosiologi, pernikahan adalah suatu ikatan lahir dan batin antara seorang laki-laki dan perempuan dalam suatu hubungan suami istri yang diberikan kekuatan sanksi-sanksi sosial. Dengan demikian keluarga merupakan kesatuan 


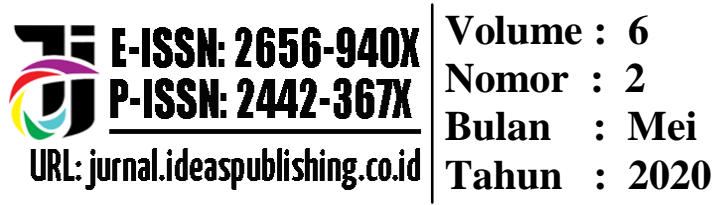

sosial yang dibentuk melalui perkawinan, yaitu penyatuan seksual antara dua orang dewasa yang diakui dan disetujui secara sosial (Setiyadi, 2006).

Pernikahan itu sendiri mempunyai arti penting dalam kehidupan manusia. Hal ini disebabkan di dalamnya ada unsur-unsur hak dan kewajiban masing-masing pihak. Contohnya, menyangkut masalah kehidupan kekeluargaan yang harus dipenuhi, baik hak dan kewajiban suami istri maupun keberadaan status perkawinan, anak-anak, kekayaan, waris dan faktor kependudukan di dalam tatanan kehidupan bermasyarakat.

Pernikahan dalam berbagai aspek memiliki sebuah makna yang berbeda. Biasanya, hal itu tergantung dari sudut pandang mana kita melihat pernikahan tersebut. Pernikahan sendiri tidak bisa terlepas dari nilai-nilai yang terkandung di dalamnya. Dengan berbagai faktor yang ada dalam pernikahan, menjadikan sebuah keberagaman makna dan budaya yang terus berkembang sesuai dengan perkembangan zaman. Oleh sebab itu, makna pernikahan bisa kita sesuaikan dengan sudut pandang yang kita gunakan, yaitu bisa dari sudut pandang agama, Undang-Undang Negara Indonesia, serta adat dan tradisi.

Indonesia memiliki kekayaan yang besar berupa keragaman tradisi dan adat-istiadat. Keberagaman di sini mencakup berbagai aspek kehidupan bermasyarakat, salah satunya adalah tradisi dan adat istiadat pernikahan. Model pernikahan sendiri ialah sebuah hal yang menarik dalam pelaksanaannya. Dengan keberagaman masyarakat yang ada di Indonesia menjadi banyak pula perbedaan tradisi dan adat istiadat pernikahan yang dilaksanakan di Indonesia. Ada beberapa daerah di Indonesia yang menganut sistem pernikahan endogamy, yaitu pernikahan yang mengharuskan menikah dengan suku, klen, atau etnis yang sama dan bahkan dengan kerabat dekat. Perkawinan sedarah atau perkawinan inses (incest) bahkan menjadi tradisi dan sistem pernikahan di salah satu suku terpencil di pedalaman Gorontalo, yaittu suku Polahi.

Di pedalaman hutan Boliyohuto Provinsi Gorontalo, hidup beberapa kelompok masyarakat nomaden yang lebih dikenal dengan sebutan suku Polahi. Menurut sejarah, suku Polahi adalah masyarakat pelarian pada zaman Belanda. Masyarakat suku polahi menganut perkawinan sedarah. Jika satu keluarga memiliki anak laki-laki dan perempuan maka mereka otomatis akan dinikahkan dengan saudaranya tersebut. Jadi, anak-anak mereka sekaligus menjadi menantu mereka. Bahkan sang ibu bisa menikahi anak lelakinya dan sang ayah bisa menikahi anak perempuannya. 


\section{Volume : 6 \\ Nomor : 2 \\ Bulan : Mei \\ Tahun : 2020

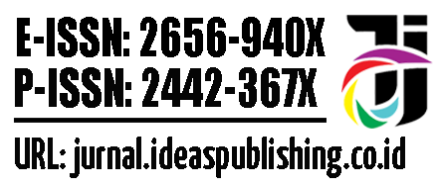

Sementara itu, Undang-Undang nomor 1 tahun 1974 tentang perkawinan. pada Bab II Pasal 8 membahas beberapa larangan perkawinan yaitu berhubungan darah dalam garis keturunan lurus ke bawah atau ke atas, berhubungan darah dalam garis keturunan menyamping yaitu antara seorang saudara dengan saudara, orang tua dan antara seorang dengan saudara neneknya, dilarang menikah. Oleh karena itu, fenomena suku Polahi menarik untuk dikaji secara ilmiah.

Incest berasal dari kata bahasa Inggris incest yang berasal dari bahasa Latin incestus, yang memiliki arti umum tidak murni, tidak suci. Adapun dalam pengertian modern sempit kata sifat yang berasal dari incest muncul di abad ke-16 (Oxford Concise Dictionary of Etymologi). Sebelum adanya istilah Latin, incest dikenal Anglo Saxon sebagai sib-leger (dari 'kekeluargaan' sibb + leger 'berbohong') atau maeghaemed (dari kerabat maeg', orang tua + haemed' hubungan seksual) tetapi dalam kurun waktu tertentu, kedua kata tersebut lebih mengarah pada penggunaan istilah seperti incester dan incestual (Conyers dkk., 2002).

Incest atau inses dalam kamus besar bahasa Indonesia adalah hubungan seksual antara orang-orang yang bersaudara dekat yang dianggap melanggar adat, hukum dan agama. Inses juga sering diartikan sebagai hubungan seksual yang terlarang antara kerabat dekat. Kriteria inses berdasarkan hasil penelusuran, merupakan suatu hubungan seksual yang dilakukan oleh kerabat sangat dekat dan perbuatan tersebut merupakan perbuatan yang dilarang. Namun pengertian inses maupun ruang lingkupnya belum merupakan pengertian yang baku di dalam masyarakat karena sesungguhnya batasan-batasan inses ini sangatlah bervariasi baik menurut pandangan agama, sosial-budaya, hukum, adat, bahkan kelas sosial.

Larangan perkawinan antara pria dan wanita sedarah sudah berlaku sejak zaman purba. Keadaan ini terdapat dalam adat istiadat kabilah, dalam hukum agama dan oleh berbagai macam kepercayaan. Islam sangat memperhatikan konsekuensi dari ikatan darah berupa penghormatan dan pemuliaan, maka Islam mengharamkan kaum laki-laki menikahi kaum kerabat yang sangat dekat. Yang demikian itu guna menghilangkan kesulitan dan menjadikan kehidupan di dalam lingkungan satu keluarga berjalan dengan mudah tanpa menemui kesulitan. Dalam AlQuran Surah An-Nisa ayat 23 menyatakan bahwa:

"Diharamkan atas kamu (mengawini) ibu-ibumu; anak-anakmu yang perempuan; saudara-saudaramu yang perempuan; saudara-saudara bapakmu yang perempuan; saudara-saudara ibumu yang perempuan; anak-anak perempuan dari saudarasaudaramu yang perempuan; ibu-ibumu yang menyusui kamu; saudara perempuan sepersusuan; ibu-ibu istri (mertua); anak-anak istrimu yang dalam pemeliharaanmu 


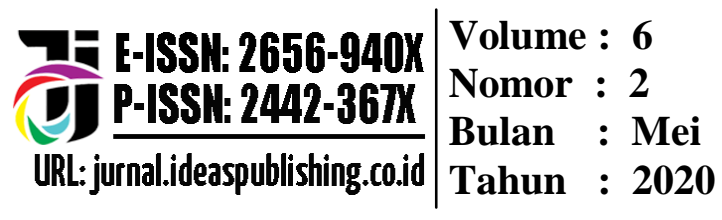

dari isteri yang telah kamu campuri, tetapi jika kamu belum campur dengan istrimu itu (dan sudah kamu ceraikan), maka tidak berdosa kamu mengawininya; (dan diharamkan bagimu) istri-istri anak kandungmu (menantu); dan menghimpunkan (dalam perkawinan) dua perempuan yang bersaudara, kecuali yang telah terjadi pada masa lampau; sesungguhnya Allah Maha Pengampun lagi Maha Penyayang." (QS. An-Nisa: 23).

Allah SWT menghalalkan pernikahan dengan seluruh perempuan selain perempuan yang diharamkan dari kalangan kerabat di atas. Larangan nikah dengan wanita-wanita tersebut di atas mengandung tujuan yang jelas, yaitu agar ruang lingkup kasih sayang manusia bertambah meluas. Selain itu, juga bertujuan untuk membiasakan kaum pria agar pandangannya kepada wanita didasarkan rasa cinta kasih sayang yang tidak dirusak oleh rangsangan nafsu seksual. Adapun cinta kasih antara pria dan wanita yang timbul dari hubungan kekerabatan tidak semestinya dicampuradukkan dengan perasaan cinta kasih yang timbul dari hubungan seksual, yang kadang-kadang bisa mengakibatkan renggangnya hubungan suami istri (Mahmud, 1947).

Hilman (1990) menguraikan Undang-Undang Nomor 1 Pasal 8 Tahun 1974 tentang perkawinan dalam telah mempertegas larangan perkawinan sedarah sebagai berikut.

1. Perkawinan dilarang antara dua orang yang berhubungan darah dalam garis keturunan lurus ke bawah ataupun ke atas.

2. Berhubungan darah dalam garis keturunan menyamping yaitu antara saudara, antara seorang dengan saudara orang tua dan antara seorang dengan saudara neneknya.

3. Berhubungan semenda, yaitu mertua, anak tiri, menantu, dan ibu/ bapak tiri.

4. Berhubungan susuan, yaitu orang tua susuan, anak susuan, saudara susuan, dan bibi/paman susuan.

5. Berhubungan saudara dengan isteri atau sebagai bibi atau kemenakan dari isteri, dalam hal seorang suami beristeri lebih dari seorang.

6. Mempunyai hubungan yang oleh agamanya atau peraturan lain yang berlaku, dilarang kawin.

Di dalam Pasal 2 Undang-Undang Nomor 1 Tahun 1974 menganut asas perkawinan agama, yaitu asas yang mengandung makna suatu perkawinan hanya sah apabila dilaksanakan sesuai dengan hukum agama dan kepercayaan masing-masing. Jadi menurut asas yang terkandung dalam Undang-Undang Perkawinan bahwa perkawinan sedarah antara saudara kandung, orang tua dan anak tidak diperbolehkan karena adanya pertalian darah atau keluarga (Hiłman, 1990). 


\section{Volume : 6 \\ Nomor : 2 \\ Bulan : Mei \\ Tahun : 2020 \\ E-ISSH: 2656-940X \\ P-ISSH: 2442-367K \\ URL:jurnal.ideaspublishing.co.id}

Karakteristik khas perkawinan di dalam kebudayaan, diantaranya tercermin dalam kenyataan sosial bahwa antara satu kawasan dengan kawasan lain umumnya memiliki dasar adat yang sama. Walaupun dasar adatnya sama, namun seringkali terjadi perbedaanperbedaan, baik dalam skala kecil maupun besar. Bahkan dalam satu kawasan budaya yang samapun, antara suku yang satu dengan lainnya boleh jadi terjadi perbedaan. Dalam beberapa suku di Indonesia, terutama suku Melayu, sistem pernikahan kekerabatan dikenal dengan tiga jenis impal yaitu impal larangan, yaitu anak-anak gadis dari ibu kandung tidak boleh kawin dengan pihak lain tanpa persetujuan dari impal larangannya. Kemudian impal biasa, yaitu anak laki-laki dari saudara ibu, serta impal langgisan yaitu anak-anak dari ibu-ibu yang bersaudara. (Muhammad dkk., 2014).

Hamamy dkk. (2011) melakukan sebuah kelompok studi konsekuensi pakar dan konselor internasional yang dilakukan di Geneva Internasional Consanguinity Workshop, membahas risiko dan manfaat yang diketahui dan dugaan pada perkawinan keluarga dekat. Mereka menemukan adanya risiko pada kesehatan bagi pasangan tersebut. Hal ini dibuktikan oleh pernyataan penyedia layanan kesehatan dan ahli genetika yang menilai keseluruhan dampak negatif perkawinan keluarga dapat meningkatkan risiko genetik terhadap keturunannya.

Selanjutnya Shieh dkk., (2013) menemukan bahwa secara keseluruhan hasil penelitian mereka menunjukkan risiko penyakit jantung kongenital meningkat pada persatuan keluarga, terutama pada tingkat perkawinan kerabat yang sangat dekat. Hal yang sama juga ditemukan oleh Bener dkk. (2006), menurut mereka generasi perkawinan kerabat dekat memiliki risiko penyakit lebih tinggi, seperti penyakit kanker, penyakit mental, penyakit hati, penyakit perutusus, hipertensi, penurunan pendengaran, dan diabetes mellitus.

Hasil penelitian Andi Tyas Surya Nugraha, yaitu Represi Terhadap Incest (Kajian Mengenai Kasus Incest di Kabupaten Aran Pandang), menyatakan secara jelas struktur sosial telah melarang perbuatan incest dalam realitas kehidupan. Struktur sosial dengan berbagai upaya melakukan deteminasi agar tidak terjadi incest di wilayahnya. Hasil penelitian Novrasilofas mengenai Dekonstruksi Pranata Erturang pada Perkawinan Semarga (Studi Kasus Masyarakat Karo di Berastagi) menyatakan bahwa implikasi yang didapat dari perkawinan semarga terdiri dari dua bentuk implikasi yaitu implikasi pada kehidupan beradat, yaitu pelaku tidak lagi mendapat tempat sebelum mereka mengesahkan pernikahan secara 


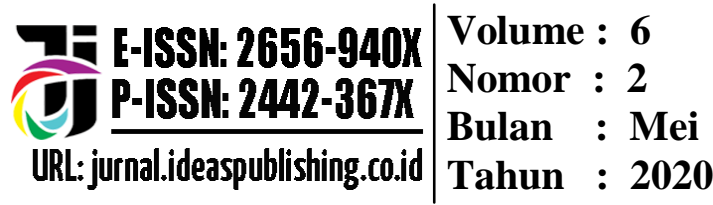

adat dan implikasi pada kehidupan bermasyarakat yaitu mereka merasa malu dan takut untuk bersosialisasi karena dianggap 'kumpul kebo'.

\section{Metode}

Penelitian ini menggunakan metode pendekatan bersifat normatif, yaitu dengan menggunakan data seperti buku, literatur, artikel maupun surat kabar, dan memaparkan datadata yang diperoleh selanjutnya dianalisis. Penelitian ini menggunakan berbagai macam sudut pandang, baik agama, hukum, adat istiadat, dan kesehatan untuk menganalisis terkait objek yang diteliti. Data yang diperlukan dapat diperoleh melalui wawancara dan studi kepustakaan, yaitu suatu teknik pengumpulan data yang diperoleh dengan menggunakan media kepustakaan dan diperoleh dari berbagai data primer serta data sekunder lainnya, seperti Undang-Undang Dasar Republik Indonesia Nomor 1 Tahun 1974 tentang Perkawinan, AlQuran dan Hadits, dan data sekunder meliputi buku-buku, hasil karya ilmiah, dan hasil penelitian, terutama buku-buku dan hasil karya ilmiah yang berkaitan dan memberikan penjelasan tentang perkawinan sedarah.

Ada dua kegiatan utama yang dilakukan dalam melaksanakan penelitian ini, yaitu studi kepustakaan dan wawancara. Studi dokumen atau studi kepustakaan yang dilakukan peneliti terhadap data sekunder yaitu berupa dokumen-dokumen yang erat kaitannya dengan perkawinan sedarah. Wawancara yang dilakukan yaitu cara untuk memperoleh informasi dengan bertanya langsung pada objek penelitian. Wawancara merupakan suatu proses interaksi komunikasi. Selain itu penelitian ini akan menggunakan teknik observasi yaitu dengan melakukan pengamatan langsung di lapangan.

Alat pengumpulan data dalam studi kepustakaan yaitu mengintervensi dokumen, artikel, hasil penelitian karya ilmiah yang membahas perkawinan sedarah. Alat pengumpul data dalam penelitian lapangan berupa daftar pertanyaan dan alat perekam suara. Data hasil penelitian akan dianalisis dengan menggunakan metode kualitatif. Analisis kualitatif merupakan tata cara penelitian yang menghasilkan data deskriptif, yaitu apa yang dinyatakan oleh responden secara tertulis atau lisan dan juga perilakunya yang nyata. Analisis yang diteliti dan dipelajari adalah objek penelitian yang utuh yang bertujuan untuk mengerti dan memahami melalui pengelompokkan dan penyeleksian data yang diperoleh dari penelitian lapangan menurut kualitas dan kebenarannya, kemudian dihubungkan dengan teori-teori, 


\section{Volume : 6 \\ Nomor : 2 \\ Bulan : Mei \\ Tahun : 2020

asas-asas, dan kaidah-kaidah yang ada. Lokasi penelitian ini yaitu masyarakat suku Polahi di seputaran Gunung Boliyohuto, Desa Tamaila Kabupaten Gorontalo Provinsi Gorontalo.

\section{Hasil dan Pembahasan \\ Makna Perkawinan Sedarah bagi Suku Polahi Adat Perkawinan Suku Polahi}

Perkawinan adalah salah satu bagian dari kehidupan suku Polahi di pedalaman Gunung Boliyohuto Desa Tamaila Kecamatan Tolangohula Kabupaten Gorontalo. Budaya yang masih melekat hingga saat ini dalam masyarakat suku Polahi yaitu setiap remaja (baik laki-laki maupun perempuan yang teleh menginjak dewasa) akan dijodohkan oleh pihak keluarga dalam kelompok tersebut. Kelompok ini terdiri dari ayah, ibu, anak-anak, bahkan dalam keluarga tersebut masih memiliki orang tua dari ayah maupun ibu (nenek dan kakek). Kelompok ini bila ada anak-anaknya yeng telah dewasa akan dinikahkan dengan saudaranya sendiri antara anak laki-laki dengan anak perempuan yang masih saudara kandung.

Menurut cerita dari keluarga $T i$ Ilimi, perkawinan sedarah bagi mereka di lingkungan suku Polahi bukan sesuatu yang tabu lagi. Alasannya, karena keinginan pihak keluarga untuk saling menikahkan di antara kelompok keluarga tersebut.

Pelaksanaan perkawinan bagi suku Polahi sangat mudah dan unik. Menurut salah seorang kepala suku yang bernama Raja, ketika melangsungkan perkawinan secara adat suku Polahi, maka pasangan yang sudah saling mencintai ini dibawa ke sungai, lalu dimandikan oleh kepala sukunya, dan diberi mantra-mantra menurut kebiasaan suku Polahi. Setelah itu mereka disatukan dan telah resmi menjadi pasangan suami istri dan diberi tempat untuk tersendiri untuk melaksanan kewajiban pasangan suami istri. Yang uniknya lagi, ada juga warga Polahi yang melangsungkan perkawinan hanya sekedar saling menyukai di antara keluarga maupun di kelompok itu sendiri dengan memohon ijin dari pihak kelurganya maupun kelompok pada kepala suku. Mereka yang sudah saling mencintai dan suka sama suka di antara warga polahi itu langsung tidur bersama dan berbulan madu pada malam pertama tanpa lagi melalui adat perkawinan suku Polahi yang biasanya pergi ke sungai untuk dimandikan oleh sang raja atau kepala sukunya.

Selain dua model dia atas, ada juga model perkawinan lainnya yang menarik perhatian peneliti, yaitu ada suku polahi baik yang wanita maupun prianya melangsungkan perkawinan dengan warga kampung yang bukan keturunan suku Polahi. Ketika peneliti mengunjungi 


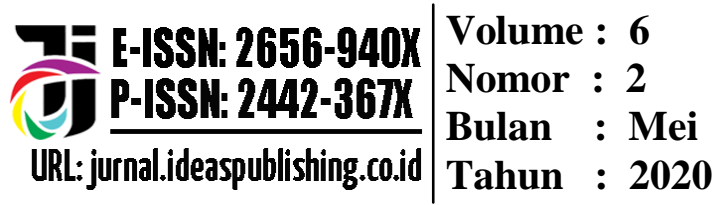

perkampungan suku Polahi ada warga Polahi wanita yang bernama Alimi melangsungkan perkawinan dengan pria warga kampung yang bukan keturunan suku Polahi. Pelaksanaan perkawinannya tidak dilaksanakan sesaui dengan budaya suku Polahi, tetapi mengikuti adat perkawinan suku Gorontalo.

Model lainnya lagi yaitu seorang kepala suku Polahi bernama Raja menikahi wanita dari kampung Gorontalo Utara bernama Putri. Proses perkawinannya tergolong singkat menurut pengakuan mempelai wanita. Berdasarkan penuturan dari Putri, awalnya kepala suku Polahi ini mencari anaknya yang hilang di sekitar kampung Gorontalo Utara. Sang Raja, Kepala Suku Polahi meminta warganya untuk mencari tahu keberadaan anaknya. Setelah beberapa hari, tersebar di telinga warga Tamaila (suku Polahi) yang akhirnya sampai juga ke telinga kepala suku bahwa anaknya berada di rumah warga yang bernama Putri yang tingga di Gorontalo Utara. Mendengar kabar tersebut, kepala suku mencari tahu siapa yang menyelamatkan anaknya itu melalui telepon. Akhirnya, tanpa menunggu waktu yang lama kepala suku langsung menuju rumah Putri tersebut di Gorontalo Utara untuk menjemput anaknya.

Cerita ini tidak sampai pada penjemputan anaknya, melainkan berlanjut terus dengan saling kontak antara kepala suku dengan Putri untuk saling mengenal satu sama lain. Entah apa yang merasuki hati sang kepala suku dan Putri, mereka saling mencintai dan suka sama suka sehingga melanjutkan ke hubungan perkawinan. Hubungan perkawinan ini dilakukan tanpa melaksanakan adat perkawinan baik adat di perkampungan keluarga putri dari suku Gorontalo maupun kepala suku sendiri dari suku Polahi. Menurut penuturan sang Putri ini, mereka hanya saling kontak telepon dengan kepala suku hingga akhirnya mereka saling mencintai dan melakukan hubungan layaknya suami istri dan resmilah kepala suku ini menjadi suami dari Putri warga kampung Gorontalo Utara. Penelusuran peneliti berlanjut kepada kepala suku Polahi, diperoleh informasi bahwa beliau telah memiliki dua istri sebelum menikah dengan Putri yang ternyata seorang janda. Suaminya meninggal dunia. Maka, Putri menjadi istri ketiga dari kepala suku Polahi dan kini tinggal bersama di pegunungan suku Polahi.

\section{Bahasa Suku Polahi}

Warga suku Polahi lahir di tengah pegunungan yang jauh dari kebisingan suara manusia dan kenderaan. Kebisingan suara walaupun lebih cocok disebut kegaduhan daripada 


\section{Volume : 6 \\ Nomor : 2 \\ Bulan : Mei \\ Tahun : 2020 \\ E-ISSH: 2656-940X \\ P-ISSH: 2442-367K \\ URL:jurnal.ideaspublishing.co.id}

kebisingan berasal dari suara binatang yang sudah menjadi bagian hidup bagi warga Polahi di Pegunungan. Hal ini mungkin berpengaruh pada bahasa mereka. Mungkin, karena lahir di kesepian, maka setiap bayi sejak dilahirkan hingga dewasa memakai bahasa tradisional khas suku Polahi yaitu bahasa Hulo-holonthalo. Dengan bahasa holonthalo ini, warga Polahi bisa beradaptasi dengan warga kampung, tetapi tidak bisa berbahasa Indonesia yang baik dan benar. Bahasa Hulonthalo adalah bahasa daerah Gorontalo. Dengan bahasa daearah inilah, suku Polahi dapat berkomunikasi dengan suku lainnya di Gorontalo. Oleh karena itu, mudah bagi suku Polahi untuk melakukan komunikasi dengan warga kampung sekitarnya, bahkan sampai menikah.

\section{Agama dan Keyakinan Suku Polahi}

Selain hanya menggunakan satu bahasa, suku Polahi tidak memiliki keyakinan salah satu agama apapun. Ketika peneliti mewawancari salah satu anggota suku Polahi yang biasa di panggil $T i$ Tua, beliau menuturkan bahwa mereka tidak tahu agama apa yang mereka anut. Dapat disimpulkan bahwa mereka ini hidup secara alami tanpa mempedulikan keyakinan atau agama apapun dalam diri mereka.

Menurut cerita dari Putri, warga Gorontalo Utara yang sudah menjadi istri Kepala Suku Polahi, mereka tidak memahami agama apaun, tetapi saya (Putri) menyampaikan kepada mereka suku Polahi sedikit demi sedikit tentang tidak dibolehkannya memakan binatang yang dilarang dalam agama, seperti babi, ular, dan binatang haram lainnya yang selama ini menjadi santapan bagi suku Polahi. Mereka biasanya memburu binatang liar di malam hari. Putri beragama Islam, maka dia berupaya memberikan pemahaman kepada suku Polahi tentang keyakinan berdasarkan agamanya untuk tidak boleh memakan bintang yang di haramkan oleh ajaran Islam.

\section{Suku Polahi di Era Digital}

Ketika peneliti berada di tengah-tengah warga Polahi, peneliti merasa heran dan penuh penasaran kepada sebagian suku Polahi yang memegang handphone, bahkan yang android. Salah seorang suku Polahi yang bernama te Akili sangat serius dengan melihat gambar dan permainan yang ada di handphone. Peneliti bertanya dengan memakai bahasa Hulonthalo kepala Akili, apakah kamu bisa membaca tulisan di handphone? Akili menjawab tidak bisa. Kemudian peneliti susul dengan pertanyaan, apa yang kau tekan ketika melihat gambar di 


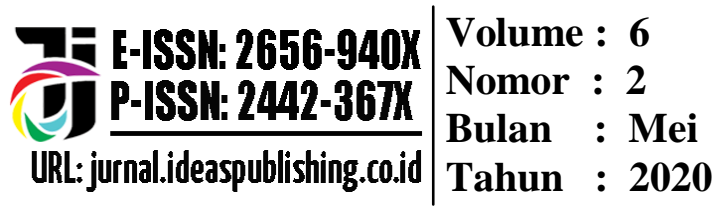

handphone? Dia hanya menjawab mengetahui apa yang harus ditekan pada layar handphone setelah diberi tahu oleh teman dari warga kampung yang sudah paham tentang handphone.

\section{Simpulan}

Kurangnya pengetahuan agama dan tingkat pendidikan (buta huruf) yang sama sekali belum menyentuh warga suku Polahi dapat menyebabkan perkawinan sesama sedarah baik sesama suku Polahi maupun beda suku tetap menjadi ciri khas bagi warga Polahi. Dari hasil penelitian, peneliti menganalisis bahwa keberadaan suku Polahi yang tidak memiliki pengetahuan dan suatu keyakinan terhadap agama apapun dapat menyebabkan suku Polahi tetap dalam tradisinya melangsungkan perkawinan sedarah sesama suku Polahi.

Peneliti berharap kepada seluruh pemangku kepentingan demi kelangsungan hidup hajat orang banyak terutama suku Polahi harus mendapat perhatian serius untuk memberikan pemahaman agar tidak lagi melangsungkan perkawinan sedarah sesama suku Polahi dan tidak pula melaksanakan tradisi perkawinan yang tidak sesuai syariat agama.

Meskipun hasil perkawinan sedarah tidak berpengaruh pada keturunan suku polahi, sebagaimana pengamatan peneliti di lapangan, tidak terjadi keturunan yang cacat fisik, maupun kelumpuhan bahkan idiot, akan tetapi untuk menghindari larangan agama mau larangan secara medis tetap harus ada upaya untuk memberi pemahaman pengetahuan kepada warga suku Polahi, agar tidak berpengaruh kepada keturunan selanjutnya.

\section{Daftar Pustaka}

Al-Aqqad, Abbas Mahmud. (1947). Filsafat Qur'an: Kairo.

Candra, M. (1990). Aspek Perlindungan Anak Indonesia: Adat, Hukum Agama. Mandar Maju: Bandung.

Bener, A. dkk. (2006). Consanguineous Marriage and Thus Effects on Common Adult Diseases: Studies from an Andegamous Population. Medical Principles and Practice.

Hamamy, Hanan. (2012). Consanguineous Marriage: Preconception Consultation in Primary Health Care Settings. Springer-Verlog.

Hadikusuma, H. (1990). Hukum Perkawinan Indonesia Menurut Perundangan. Mandar Maju: Bandung.

Kamus Besar Bahasa Indonesia. http://kbbi.web.id/inses. Diakses 11 April 2016.

L Conyers, James. (2002). Black Cultures and Race Relations. Rowman \& Littlefield. Chicago: Burham Inc., Publisher.

Nugraha, Andi Tyas Surya. Represi Terhadap Incest (Kajian Mengenai Kasus Incest di Kabupaten Aran Pandang), Volume 9, No. 2, Juli-Desember 2015. 
Novrasilofas. Dekonstruski Pranata Ertfrang $\underset{\text { Bantan }}{\text { Padja }}$

Volume : 6

Nomor : 2 Perkawinan Semarga (Studi Kasus Masyarakat Karo Berastagi). Jurnal Ilmu Sosial. Vol. 13.,No.2, 2016 (p-ISSN) 1829-5797.

Oxford Concise Dictionary of Etymologi, T.F. Hoad (ed.) (1996), p. 232.

Takari, Muhammad, dkk. (2014). Adat Perkawinan Melayu: Gagasan, Terapan, Fungsi, dan Kearifannya. Medan: USUPress.

Shieh, Joshep T.C., dkk. Congsanguinity and The Risk of Congenital Heart Disease. NIH Public Access. 2013:1-11.

https://www.biologiasyik. wordpress.com/2011/12/21/incest-perkawinan-sedarah/, diakses pada hari Kamis, 23 Agustus 2018, pukul 08.55 wita. 
TE E-ISSH: 2656-940X Volume : 6

(1) P-ISSH: 2442-367K Nomor : 2

URL:jurnal.ideaspublishing.co.id $\mid \begin{aligned} & \text { Tahun : } 2020 \\ & \text { Taho }\end{aligned}$ 